\title{
Seismic isolation for three buildings in Nicosia
}

\author{
K. Yiannouris ${ }^{1} \&$ G. C. Giuliani ${ }^{2}$ \\ ${ }^{I}$ Marathefitis-Yiannouris Architects Engineers, Nicosia Cyprus \\ ${ }^{2}$ Consultant Redesco Progetti Srl, Milan Italy
}

\begin{abstract}
The use of seismic isolation proves to be very efficient for the construction of huge commercial centres because of the savings in the price of the structures and of the safety assurance given to the visitors and to the exhibited goods. In addition to the structural analysis and design, the application of the isolation calls for the correct solution of many problems, mainly related to the connections of the isolated parts to the ones fixed to the ground. The conceptual design and the most important features of three seismically isolated buildings already completed or under construction in Nicosia are illustrated.
\end{abstract}

Keywords: seismic isolation, isolators, fail safe systems, joints, connections, buildings.

\section{Features of the seismic isolation}

The principle of the seismic isolation is the decoupling of the construction from the horizontal ground motions, which in conventional solutions generate important horizontal shear actions and bending moments in the structural frame. It is of course possible to design normal anti-seismic frames, but the necessary resistance increases the stiffness, which increases the accelerations of the structures and therefore demands additional strength, which yields an additional stiffness, and so on.

The final result is achieved in general, but the resistance can only be assessed while the horizontal accelerations of the elevated floors are higher than the ground ones: the persons staying inside can be injured and the non-structural parts of the building can be seriously damaged or destroyed.

On the contrary, the fundamental advantages of the seismic isolation technique are the assurance of the complete safety of the human lives and the absence of any damage to the goods and to the non-structural components. 
In addition, because of the limited horizontal stiffness of the isolators, which results in the limited value of the constraining forces created by the temperature and by the rheological effects of the concrete slabs, it is possible to avoid joints inside the buildings.

Important savings in the foundations and in the vertical structures (columns and bracings) are also achieved.

The selection of seismic isolation as a basic structural concept is very convenient and indeed mandatory in cases where a lack of regularity in the plan or in the elevation exists and therefore yields conspicuous eccentricity between the centroid of the masses and of the stiffness. In this case, in a normal anti seismic solution, the actions in the vertical structures would largely be increased. On the other hand, the reduction of the accelerations in the structures, given by the seismic isolation, requires significant displacements of the building and of the differential ground. Because of this requirement, the design must include a proper solution for the following details: structural joints, fail safe system, bracing system, building entrances, pipe, duct and wire connections, elevators and escalators.

\subsection{Structural joints}

The joints between the buildings and the boundary fixed parts must allow for independent relative movement of the ground and of the constructions during the earthquake, thus removing any restraint of the seismic isolation system.

\subsection{Fail safe system}

A fail safe system, having the function of limiting to the safety design values the displacements of the isolators, is needed.

It can be composed of rubber hemispherical bumpers which act against buttresses protruding from the reinforced concrete columns or shear walls located in the underground floor; the construction gap between the bumpers and the concrete is set according to the isolator shear displacement, see fig. 1.

Another solution is composed of groups of two steel plates being anchored to the bottom of a floor slab and to the top of the shear walls respectively; because of the vertical displacement of the isolators created by the horizontal shear strain, the two plates will be touching each other at the design horizontal displacement. The requested precise vertical gap between the two plates is given by construction details allowing for the necessary adjustments, see fig. 2.

\subsection{Bracing system}

Although the isolation system highly reduces the horizontal accelerations induced by the earthquake, a light bracing system is normally provided in order to avoid any damage to the brittle non-structural elements.

The bracing is exploited with different shapes that best fit with the functional and architectural requirements of the buildings, see fig. 3 . 


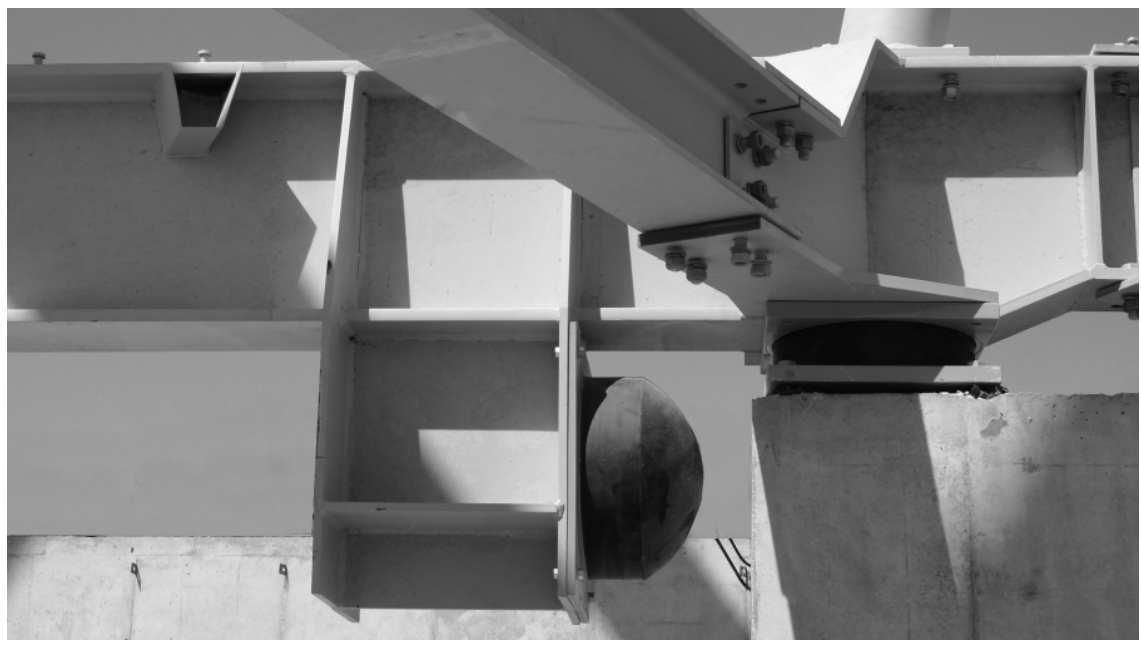

Figure 1: A seismic isolator and the fail-safe system composed of a hemispherical rubber bumper.
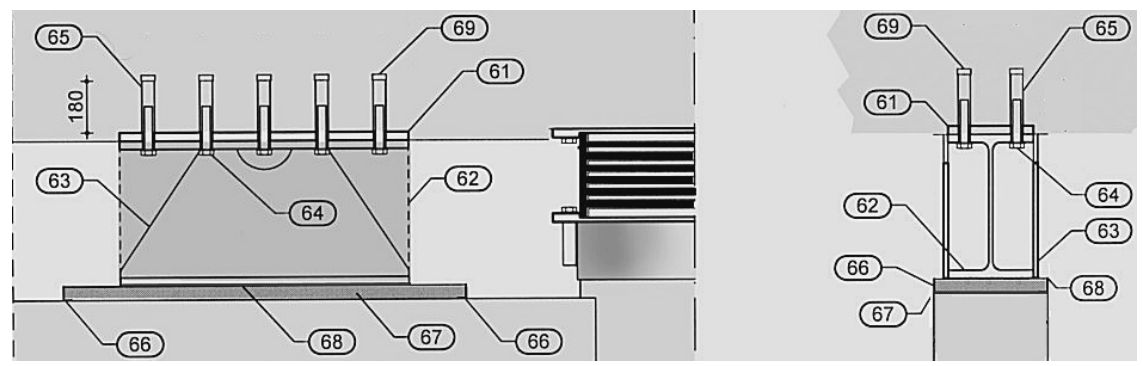

Figure 2: A fail-safe system based on touching plates.

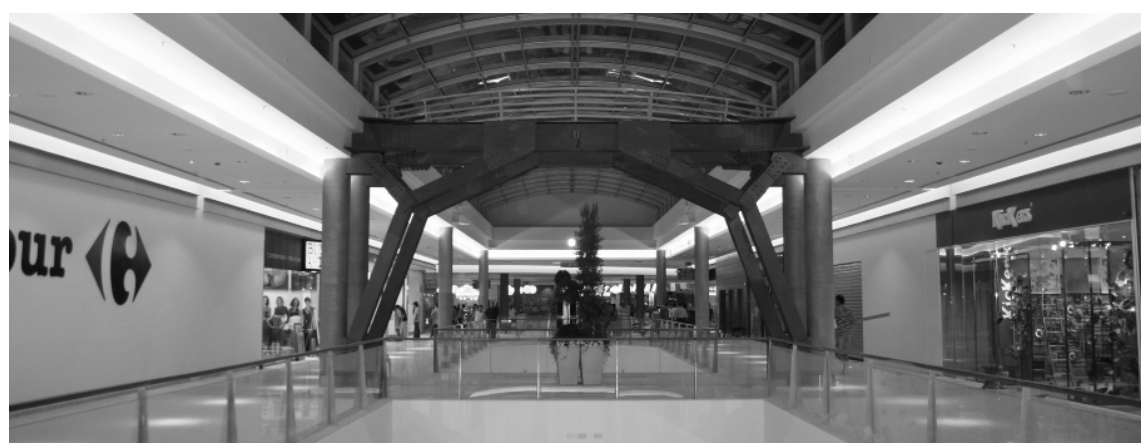

Figure 3: A transversal bracing parallel to a structural joint. 


\subsection{Non-structural details}

\subsubsection{Building entrances}

All the pedestrian and light traffic connections of the building, to the nonisolated parts must allow for the two way relative displacements of the ground and of the structure, see fig. 4. This condition applies to the entrances into the buildings, both at ground level and at exits from outer elevators and to passages connecting adjacent buildings.

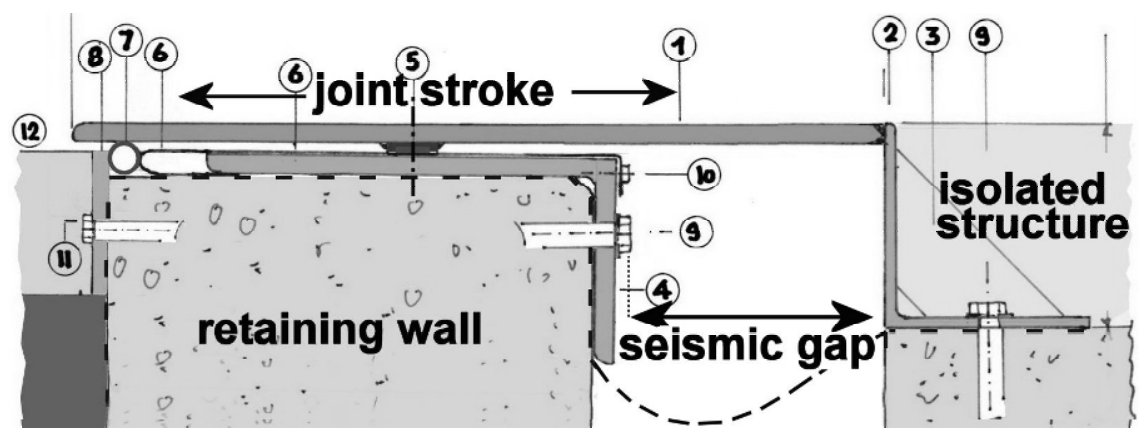

Figure 4: $\quad$ A two way sliding joint for the building entrances.

\subsubsection{Pipe, duct and wire connections}

All the equipment connections of the building to fixed, non-base isolated parts have to allow for the two-way relative displacements of the ground and of the structure. This condition applies to pipe, duct and wire entrances into the buildings and to passages connecting adjacent buildings, see fig. 5 .

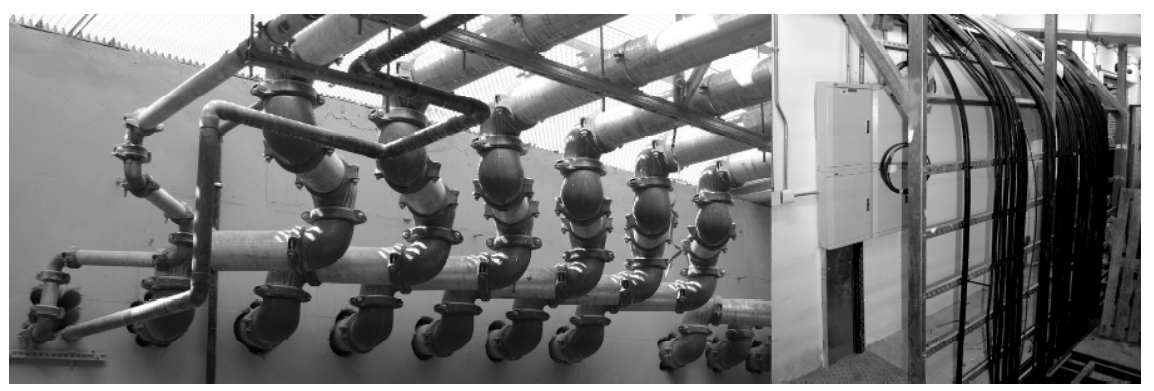

Figure 5: A two way coupling joint for the building pipe rack and the similar arrangement for the cables.

\subsubsection{Elevators and escalators}

All the supporting structures of the elevators and of the escalators, supported by the base isolated buildings must not have any contact with the fixed parts, see fig. 6 . 


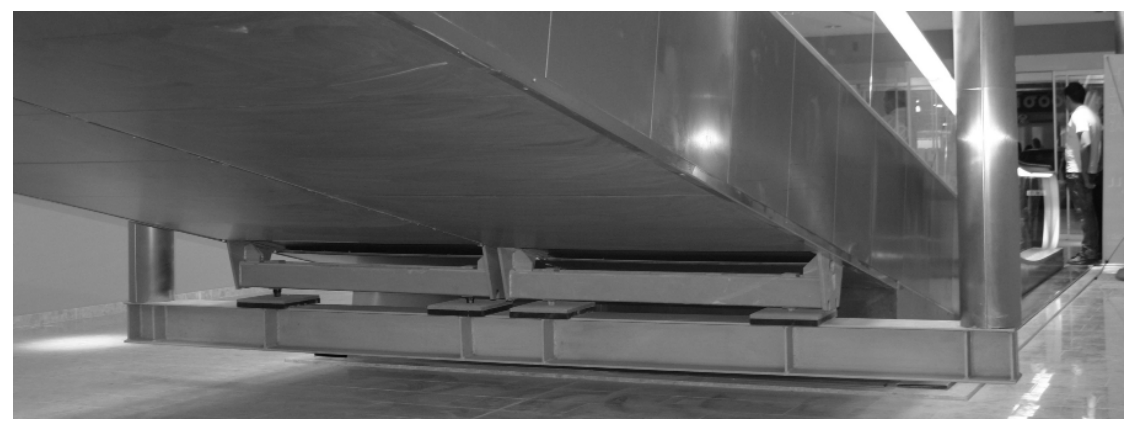

Figure 6: An escalator suspended from the isolated level in order to avoid any constraint from the fixed level.

\section{Structural analysis and verification}

The dimensioning and the verification of the seismically isolated structures has to be performed by a complete structural analysis by using a $3 \mathrm{D}$ finite element model, in static and dynamic field.

A modal analysis of the whole structure is performed, taking into account the real stiffness of the whole composite system and the response spectrum is applied.

All composite sections are represented by their real geometry calculated for a long time ratio of the elastic moduli of concrete and of steel.

The concrete deck, which is normally cast over a corrugated steel sheet, is represented by plate elements whose properties correspond to the equivalent concrete thickness of the corrugated slab.

All materials are taken into account with their real properties.

\section{Seismic isolators}

The specifications for the seismic isolators are defined by prEN15129, although not approved yet by CEN. All the tests are performed according EN1337-3-2005, see fig. 7.

The standard type is composed of multiple layers of a high damping rubber compound and of steel plates vulcanised together thus featuring stiffness and damping characteristics, see table 1.

\section{Seismic isolation in Nicosia - Cyprus}

According to the geotechnical reports related to the Nicosia area, there is no danger of the soil liquefaction hazard produced by earthquake; therefore the following parameters hold for the seismic action:

ground acceleration $\mathrm{g} / \mathrm{a}=0.10$;

coefficient of building importance $\mathrm{I}=1.00$; 


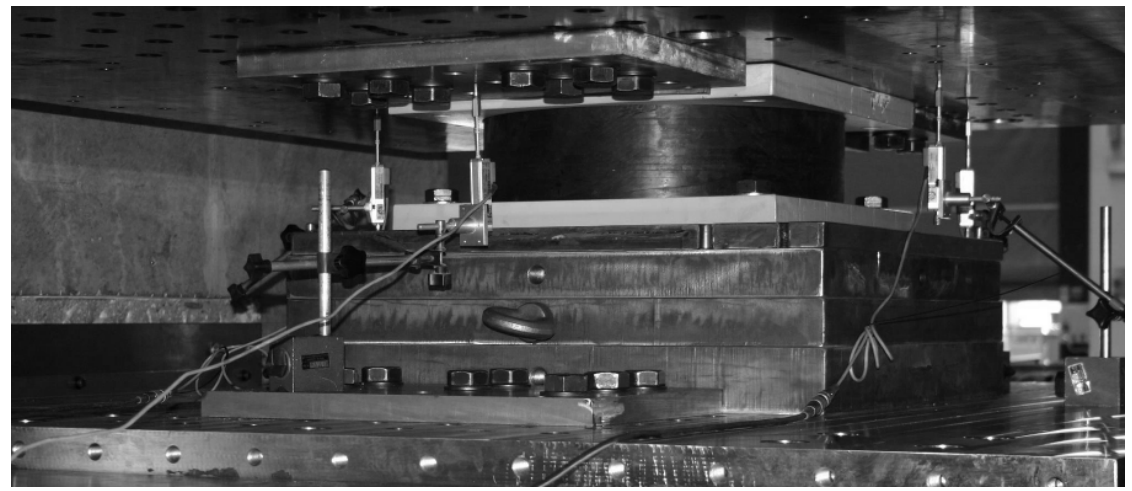

Figure 7: A seismic isolator inside the testing rig for assessing the capability of developing the design horizontal strain while supporting the vertical loads.

Table 1: Typical characteristics of the isolators of different sizes used in buildings.

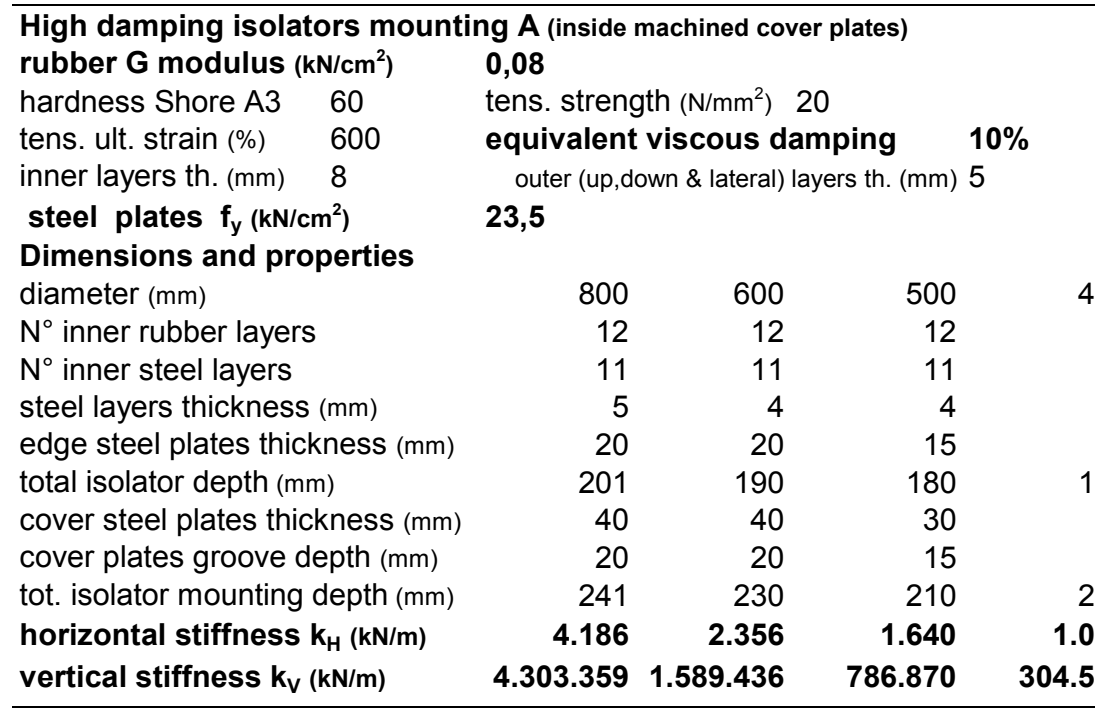

coefficient of spectrum increasing related to the structural damping $5 \% \beta_{0}=2.5$; kind of ground A (dense sand and gravel layers); with the following parameters for the acceleration spectrum shape, see fig. 5: $\mathrm{S}=1.00, \beta_{0}=2.5, \mathrm{k}_{1}=1, \mathrm{k}_{2}=2, \mathrm{~T}_{\mathrm{B}}=0.10 \mathrm{~s}, \mathrm{~T}_{\mathrm{C}}=0.40 \mathrm{~s}$ and $\mathrm{T}_{\mathrm{D}}=3 \mathrm{~s}$.

The elastic design spectrum resulting from Euro Code 8 is governed by the peak acceleration $\mathrm{a} / \mathrm{g}=0.205$, see fig. 8 . 


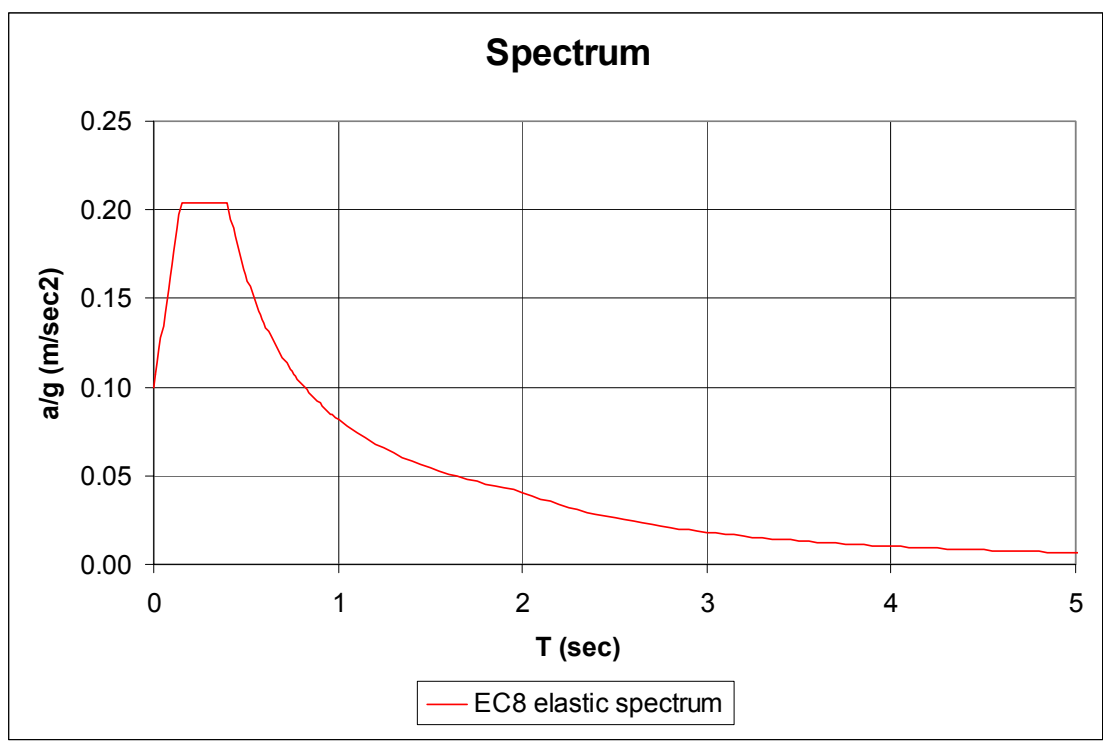

Figure 8: $\quad$ The EC8 elastic design spectrum for the Nicosia grounds.

Setting the quasi rigid body periods of the structure at around $2.5 \mathrm{~s}$, the elastic response spectrum yields the input acceleration $\mathrm{a}_{\mathrm{i}} / \mathrm{g}=0.025 \mathrm{~g}$

Although in Nicosia the expected seismic hazard is not very high, the benefits of the base isolation result in a reduction of the construction price also.

For a background reference, in June 2001, the co-author G. C. Giuliani gave two lectures on the subject during the seminar "Seismic isolation" held in Nicosia and stressed the relevant convenience which was based on his experience with the design (1987) and supervision (1989) of the Telecom Centre, located in Ancona - Italy. It constitutes the first Italian example of seismic isolation and was subjected to unique full-scale tests; the project was internationally recognized by the award of the 1993 Munro prize for the paper on the subject published on Engineering Structures [1].

Nowadays seismic isolation was applied to three important buildings in Nicosia: two already completed (the Shacolas Mall and the ITTL Trade Tourist and Leisure Park) and one, already designed and in the construction phase at the date (Fliska Holdings).

For all these projects, which are illustrated in the following paragraphs, the general design was performed by the in Nicosia based firm MaratheftisYiannouris, Architects - Engineers, while the structural design was developed by the in Milano based firm Redesco srl. with G. C. Giuliani as Consultant

\subsection{Shacolas mall}

The elevated shopping mall features a ground level above the underground parking, the first floor and the roof; the construction is constituted by two buildings separated by a horizontal structural joint, see fig. 9 . 
The dimensions of each one of the building decks are 90 by $112 \mathrm{~m}$.

The centre lines are typically set at $10.00 \mathrm{~m}$ in the transverse direction parallel to the main beams and at $16.00 \mathrm{~m}$ in the longitudinal direction parallel to the secondary beams.

At ground level the decks are supported by high damping steel rubber isolators bearing on the top of reinforced concrete columns protruding from the foundations, see fig. 10 .

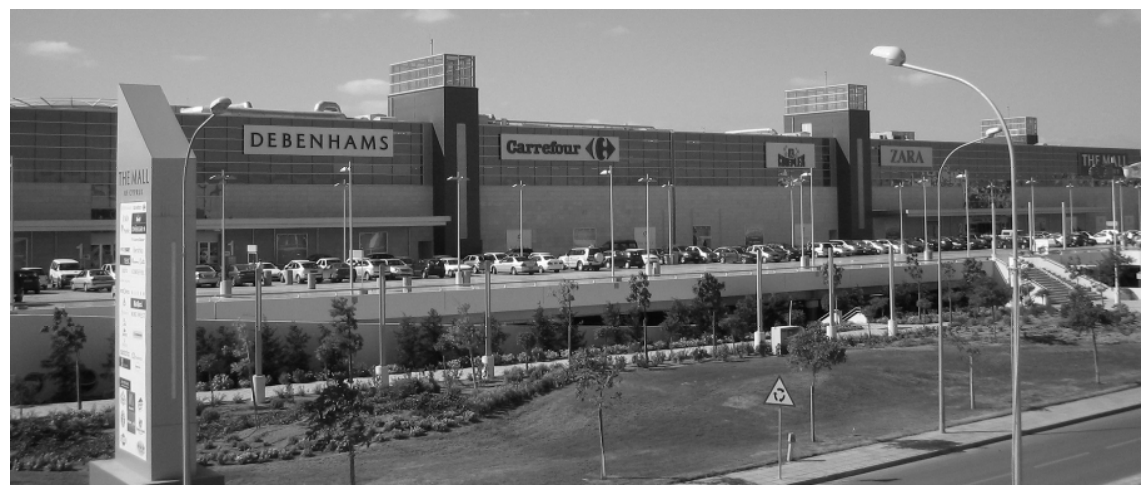

Figure 9: View of the Nicosia Shacolas Emporium Park completed building.
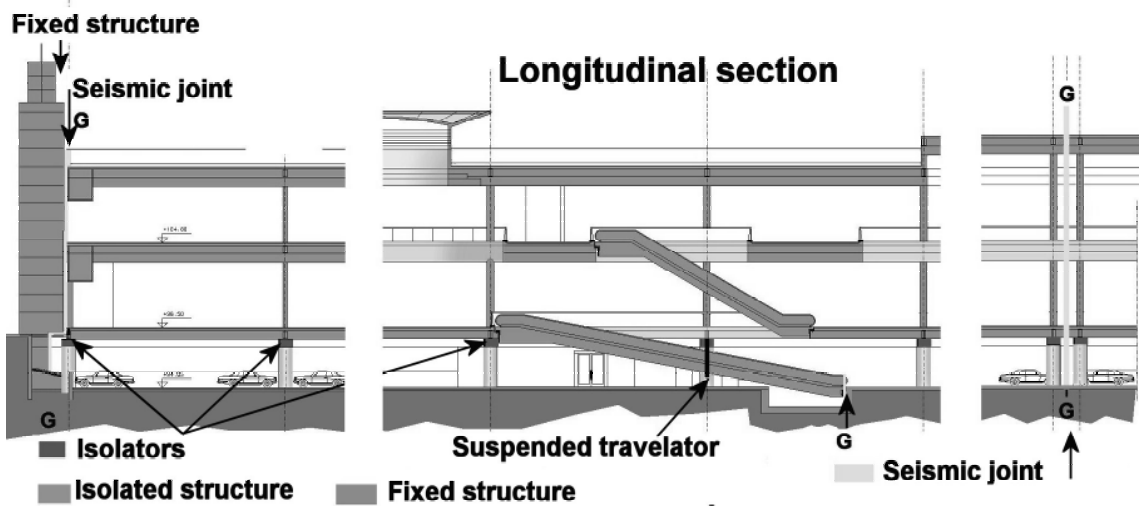

Figure 10: The seismic isolation devices of the Shacolas Emporium Park laid under the ground floor.

All of the decks feature a steel-concrete composite structure composed of main and secondary hot rolled steel beams and of a concrete slab.

The columns are continuous from the ground floor up to the roof and constituted by hot rolled steel shapes with the quite general addition of side plates added by in shop welding.

Both the secondary and the main girders are continuous over the supports (that are the columns for the main beams, the columns and the main beams for the secondary ones. 


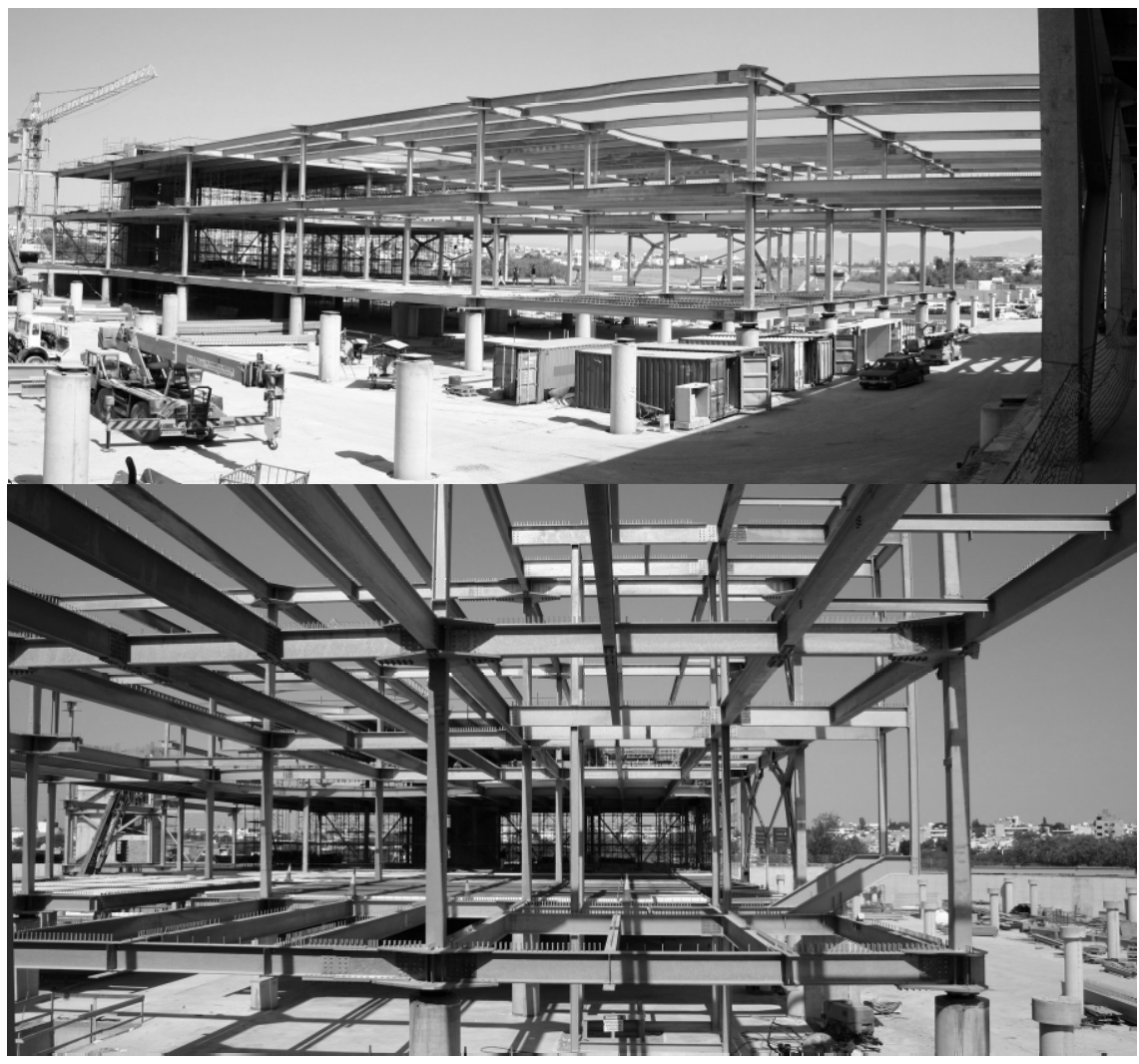

Figure 11: The Shacolas Emporium Park steel skeleton.

The main beams are HEAA, HEA and HEB rolled shapes with bottom added plates in the end bays, while the secondary beams are light IPEA rolled shapes and normal IPE in the end bays; shear studs are shop welded on the upper flanges of the beams, see fig. 11 .

All the in situ connections between the steel girders and columns are of the bolted type and are designed for achieving the full resistance of the connected shapes independently from the value of the actions resulting from the analysis; this requirement was selected to give the structure the necessary redundancy to resist earthquake hazards, higher than the expected ones.

\subsection{ITTL trade tourist and leisure park}

The building features a trapezoidal plan with an elevated part and underground parking, which is extended outside the projection of the building on the northern side.

The building plan and the elevation are non-regular, the centroids of the mass and of the stiffness are separated and therefore the use of the seismic isolation is very effective for reducing the applied dynamic torque. 
Because of the limited mass of the building the requested horizontal stiffness of the isolating system is limited also and therefore isolators and freely sliding bearings were used on the top of the underground shear walls and columns respectively, see fig. 12 .

The dimensions of the building decks lay inside a rectangle with 137 by $55 \mathrm{~m}$ sides in the underground while the similar dimensions for the elevated part are 122 by 44; the floor heights are 4.00 / 6.00 / $5.00 \mathrm{~m}$ for the underground / ground / first floor respectively.

The centre lines of the inner columns are typically set at $10.00 \mathrm{~m}$ in the transverse outer bays close to the longitudinal facades while the inner bays are variable from around $14 \mathrm{~m}$ to $0 \mathrm{~m}$; the longitudinal centre lines are typically set at $8.00 \mathrm{~m}$ in the underground and to $16.00 \mathrm{~m}$ in the elevated part, while the outer columns are set at $24.00 \mathrm{~m}$ centre lines, see fig. 13 .

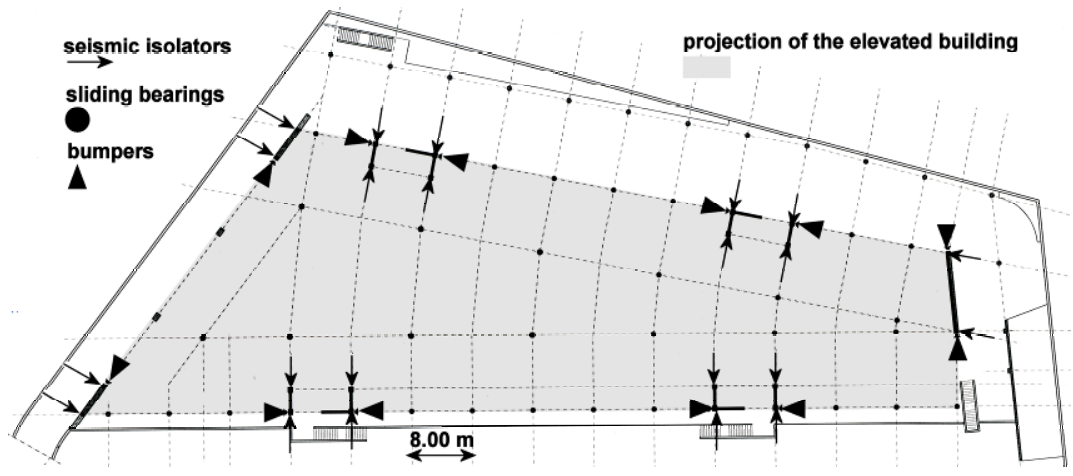

Figure 12: The ITTL non-regular plan and the position of the anti seismic devices.

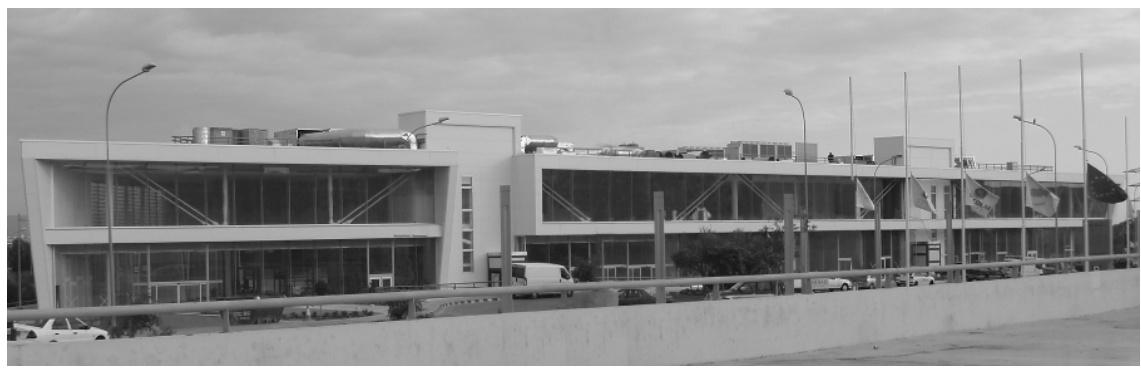

Figure 13: The ITTL $24.00 \mathrm{~m}$ span outer girders.

At the ground level the decks are supported by pot type sliding bearings.

The bearings are located on the top of the reinforced concrete columns protruding from the foundations, while on the staircase and shear walls the supports are provided by high damping steel rubber isolators; this coupled system of supports seismically isolates the whole building. 
All of the decks feature a steel-concrete composite structure composed of main and secondary hot rolled steel beams and of a concrete slab; all of the columns are constituted by pipes continuous from the isolation level up to the roof.

The reinforced concrete shear walls were split in two parts, to be erected by matching the concrete casts, a connection with shear studs laid across the vertical common surface was provided; a satisfactory ductility was therefore achieved.

In the basement the reinforced concrete cylindrical columns have a $0.60 \mathrm{~m}$ diameter, while steel pipe diameters of 457 and $257 \mathrm{~mm}$ are used above the ground floor.

The steel columns are continuous from the bearing and isolator level up to the roof and are prefabricated with vertical and horizontal welded plates for the bolted connections with the horizontal beams which.

All the structure is arranged as a 3D frame with columns, beams, concrete slabs and bracings, fig, 14.

Both the secondary and the main girders, as well as the concrete slab, are continuous over the bays.

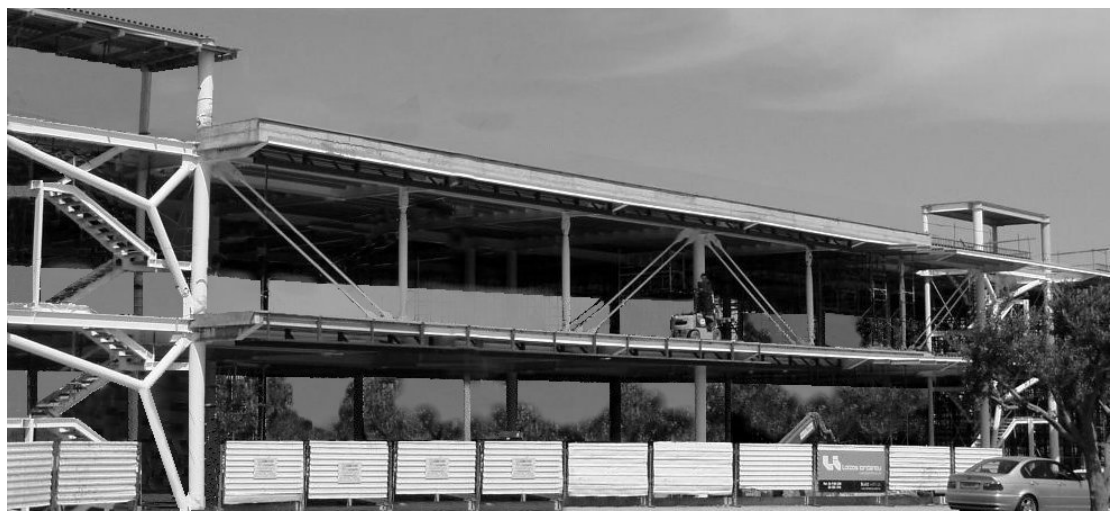

Figure 14: The ITTL longitudinal bracing system.

The beams are HEAA, HEA and HEB rolled shapes with added plates in the larger span bays; shear studs are shop welded on the upper flanges of the beams.

Along the longitudinal facades laid in East to West direction, continuous trussed girders are laid, over the typical $24.00 \mathrm{~m}$ span, between the first and the roof floors and bear the relevant transverse beams.

The truss chords are constituted by couples of UPN 350 mutually connected by welded vertical plates; $273 \mathrm{~mm}$ diameter pipes are used for the struts while couples of 460 carbon steel M85 bars are used for the ties; Macalloy forks and pins are used for the connections of the struts and the ties, see fig. 15.

The skew North-West façade structure is composed of two couples of inclined struts and by bracing trusses all connected by the floor beams; the East façade is composed of columns and transverse beams integrated with the bracing 


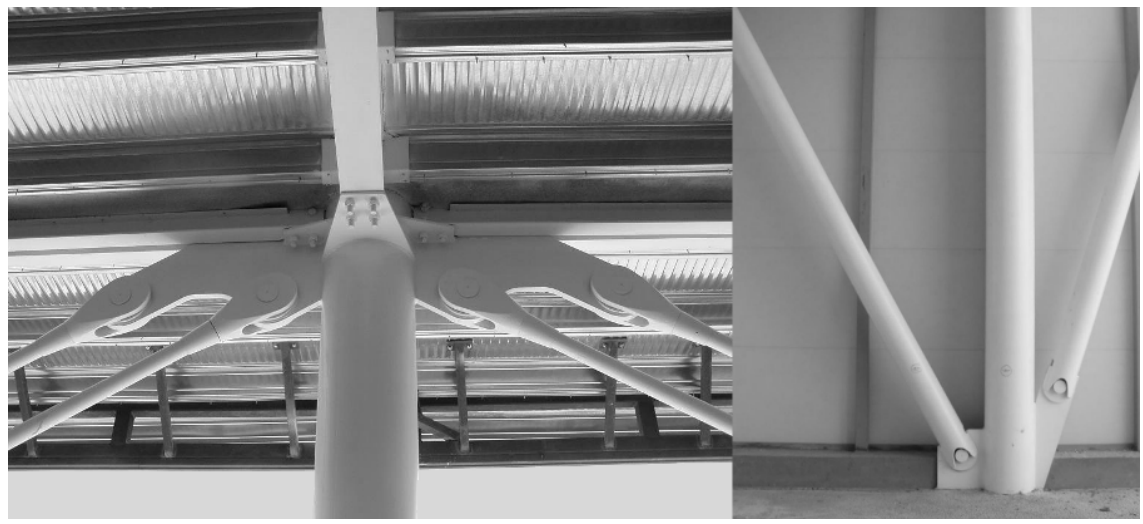

Figure 15: Details of the ITTL $24.00 \mathrm{~m}$ span outer girders.

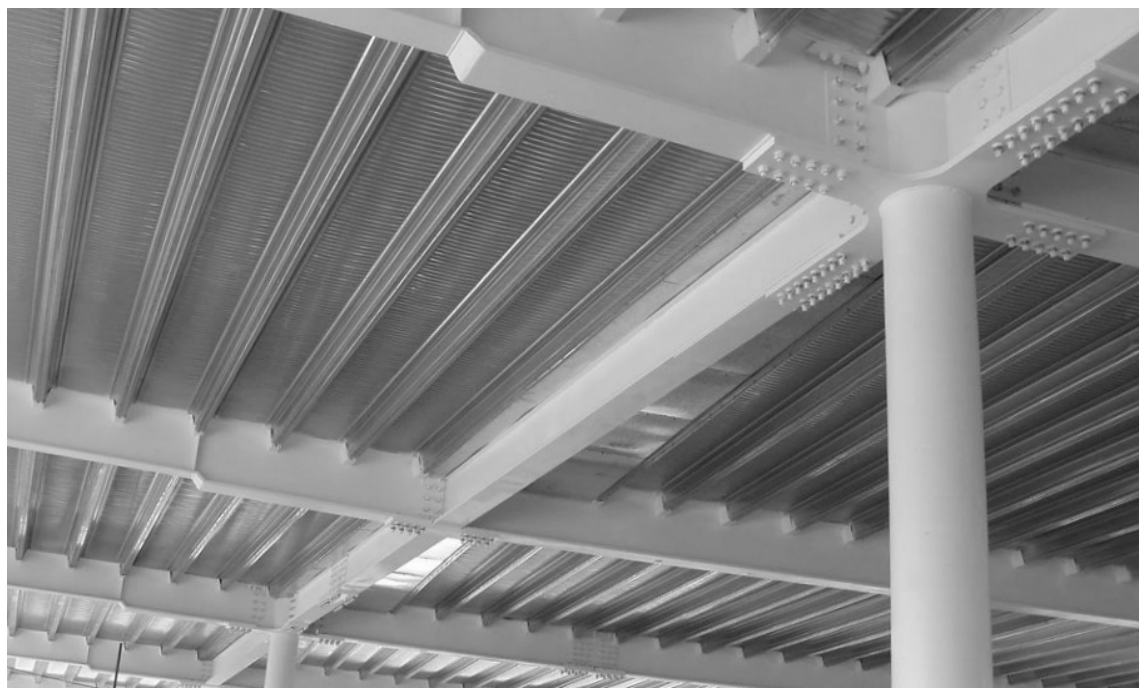

Figure 16: Details of the ITTL $24.00 \mathrm{~m}$ span.

Because of the reduction of the actions granted by the seismic isolation, the steel-concrete composite decks are very light and shaped with elegant details for leaving all the structures in sight inside the building, see fig. 16.

\section{References}

[1] Giuliani, G.C., Structural design, analysis and full-scale tests of seismically isolated buildings, Engineering structures 1993, Vol.15, ํ2 - p. 102-116 